\title{
DIFERENTES REPRESENTAÇÕES DOS NÚMEROS RACIONAIS: UMA ANÁLISE DE LIVROS DIDÁTICOS DE MATEMÁTICA
}

\section{CLARICE DE ALMEIDA MIRANDA ${ }^{i}$}

\author{
Universidade Estadual do Oeste do Paraná \\ E-mail: clari.miranda@hotmail.com
}

\section{VERIDIANA REZENDE}

\section{Universidade Estadual do Paraná \\ E-mail: rezendeveridiana@gmail.com}

\section{RESUMO:}

Apresentamos neste trabalho os resultados de uma pesquisa que teve como objetivo analisar livros didáticos de Matemática do 8 o ano do Ensino Fundamental, à luz da teoria dos Registros de Representação Semiótica, presentes no Capítulo destinado aos estudos dos números racionais. A investigação abrangeu duas obras do 8 ano, aprovadas pelo Programa Nacional do Livro Didático PNLD 2014, adotadas nas escolas pertencentes ao Núcleo Regional de Educação - NRE de Campo Mourão - Paraná. A análise teve como foco o capítulo de cada um dos livros que se estuda o conjunto dos números racionais, em relação a sua abordagem teórica e às tarefas. A análise mostrou diferenças significativas entre as obras no que se refere às representações semióticas. Estes fatos indicam a importância da escolha das obras e dos professores diversificarem as tarefas em sala de aula.

\section{PALAVRAS-CHAVE:}

Ensino de Matemática, Educação Básica, Números.

\section{DIFFERENT REPRESENTATIONS OF RATIONAL NUMBERS: ANALYSIS OF MATHETMATICS} TEACHING BOOKS

\section{ABSTRACT:}

We present in this work the results of a research that had as objective to analyze didactic books of Mathematics of the 8th year of Elementary School, in light of the theory of the Registers of Semiotic Representation, present in the Chapter for the study of rational numbers. The research included two works from the 8th grade, approved by the National Program of Didactic Book - PNLD 2014, adopted in the schools belonging to the Regional Nucleus of Education - NRE Campo Mourão - Paraná. The analysis focused on the chapter of each of the books that study the set of rational numbers, in relation to their theoretical approach and tasks. The analysis showed significant differences between the works in terms of semiotic representations. These facts indicate the importance of choosing the works and the teachers to diversify the tasks in the classroom. 


\section{D|EDebates

\section{KEYWORDS:}

Mathematics Teaching, Basic Education, Numbers.

\section{INTRODUÇÃO}

Apresentamos neste artigo os resultados de uma pesquisa de iniciação científica desenvolvida pela primeira autora, sob orientação da segunda, relacionada à abordagem dos números racionais em livros didáticos, sob a ótica da Teoria dos Registros de Representação Semiótica de Raymond Duval. As obras analisadas referem-se a dois livros de 8 o ano do Ensino Fundamental, de coleções aprovadas pelo Programa Nacional do Livro Didático - PNLD 2014.

O PNLD é um programa do governo federal, que propicia subsídios ao trabalho pedagógico dos professores da Educação Básica por meio da distribuição de livros didáticos a todos os alunos de escolas públicas do Brasil ${ }^{1}$. Os professores das disciplinas contempladas no PNLD recebem o manual do professor, que consiste do livro do aluno acrescido de uma parte específica para o professor, que contém reflexões relacionadas aos conteúdos explorados na obra, avaliação, metodologias de ensino, objetivos educacionais segundo documentos curriculares nacionais, entre outras.

A cada ano o PNLD avalia livros de um determinado nível escolar: anos iniciais do ensino fundamental, anos finais do ensino fundamental ou ensino médio. Após passar pelo processo de avaliação, os livros aprovados chegam até as escolas para que os professores e equipes pedagógicas possam realizar a escolha das coleções que serão adotadas pela instituição. 
Segundo os Parâmetros Curriculares Nacionais - PCN para a disciplina de Matemática, o livro didático é um dos materiais de muita influência na prática pedagógica dos professores. Assim, e considerando as diferentes coleções aprovadas a cada PNLD é importante que a escolha do livro pelos professores seja criteriosa, levando em conta os objetivos educacionais gerais, as especificidades regionais de cada escola e de cada disciplina.

A disciplina de Matemática, por exemplo, tem uma especificidade que a difere das demais disciplinas - os conceitos matemáticos são abstratos, e seu estudo ocorre somente por meio de suas representações. Desse modo, defendemos, assim como Duval (2012), que a essência da compreensão de um conceito matemático está em não confundir o objeto matemático com suas representações, e em reconhecê-lo em suas diferentes formas.

Segundo Duval (2012), para que ocorra a aprendizagem de um conceito é necessário coordenar ao menos dois registros de representação de um mesmo objeto matemático e [...] esta coordenação se manifesta pela rapidez e a espontaneidade da atividade cognitiva de conversão (DUVAL, 2012, p.282). Para o pesquisador, a conversão refere-se a transitar espontaneamente de um registro de representação para outro registro.

Para o desenvolvimento desta pesquisa, optamos por analisar as diferentes representações dos números irracionais exploradas nos livros didáticos. A escolha por este conceito decorre do fato de que uma das autoras deste trabalho desenvolve desde o ano de 2009 uma ampla pesquisa relacionada à compreensão de alunos de diferentes níveis de ensino no que se refere aos números racionais, irracionais e reais. E a abordagem desses números dos livros didáticos de matemática podem influenciar na compreensão desses conceitos pelos alunos. 
O conteúdo números racionais deve ser estudado desde o segundo ciclo do Ensino Fundamental, 4ㅇ e 5o anos, sendo seu conceito consolidado no decorrer dos anos finais do Ensino Fundamental (BRASIL, 1997). E, no que se refere a este conceito, notamos que ele pode ser estudado por meio de suas diferentes representações, que podem se tornar mais complexas, ao avançar os estudos e situação proposta, bem como no cotidiano, de acordo com o contexto em que se apresentam. Por exemplo, é comum empregar a expressão 1/4 xícara de leite, em uma receita, ao invés de 0,25 xícaras de leite; e dizer que o preço de determinado produto aumentou em 2,4 \%, e não 24/1000 ou 3/125.

Desse modo, considerando a perspectiva de Duval relacionada a necessidade de diferentes registros de representação para a compreensão de um conceito matemático; considerando que para o estudo dos números racionais os Parâmetros Curriculares Nacionais - PCN presumem que [...] a construção do conceito de número racional pressupõe uma organização de ensino que possibilite experiências com diferentes significados e representações [...] (BRASIL, 1997, p.70); e, ainda, que o livro didático é um grande aliado relacionado à prática do professor em sala de aula; decidimos desenvolver este trabalho com o objetivo de analisar livros didáticos de Matemática do Ensino Fundamental de escolas públicas, aprovados pelo Programa Nacional de Livros Didáticos - PNLD 2014, no que se refere às diferentes representações desses números.

\subsection{OS REGISTROS DE REPRESENTAÇÃO SEMIÓTICA E OS NÚMEROS RACIONAIS}

Raymond Duval é filósofo e psicólogo de formação. Durante seus estudos no Instituto de Pesquisa sobre o Ensino de Matemática - IREM de Estrasburgo na França, desenvolveu uma teoria cognitiva denominada de Registros de Representação Semiótica (DUVAL, FREITAS, REZENDE, 2013). Segundo o pesquisador, 


\section{D|EDebates

[...] a originalidade da atividade matemática está na mobilização simultânea de ao menos dois registros de representação ao mesmo tempo, ou na possibilidade de trocar a todo o momento de registro de representação (DUVAL, 2003, p.14).

Para Duval (2012b), a limitação em apenas um registro de representação semiótica [...] não favorece em nada as transferências e as aprendizagens ulteriores: torna os conhecimentos adquiridos pouco ou não utilizáveis em outras situações aonde deveriam realmente ser utilizados (p.283). O pesquisador acrescenta que a compreensão de um conceito limitada a apenas um registro [...] conduz a um trabalho às cegas, sem possibilidade de controle do "sentido" daquilo que é feito (p.283).

De acordo com a Teoria das Representações Semióticas (DUVAL, 2003), existe um paradoxo cognitivo do pensamento matemático quando falamos de conhecimento matemático e suas formas de representação. Pois, os objetos matemáticos não são jamais acessíveis perceptivamente ou instrumentalmente (microscópio, telescópio, aparelhos de medida, etc.). O acesso aos objetos matemáticos passa necessariamente por representações semióticas (DUVAL, 2003, p.21). Assim, a questão está em como não confundir o objeto matemático com sua forma representada, sendo o acesso a ele restrito às representações.

Para Duval, as representações semióticas [...] são produções constituídas pelo emprego de signos pertencentes a um sistema de representações que tem inconvenientes próprios de significação e de funcionamento (DUVAL, 2012, p.269). Como, por exemplo, uma figura geométrica, um gráfico, uma expressão algébrica que são representações semióticas que pertencem a sistemas semióticos diferentes.

Duval (2003) classifica quatro grandes tipos de registros, são eles: a língua natural (associações verbais, conceituais, forma de raciocinar), os sistemas de escritas (numéricas, algébricas, simbólicas), as figuras geométricas planas ou em 
perspectivas (operação operatória e não somente discursiva, construção com instrumentos) e os gráficos cartesianos (mudanças de sistemas de coordenadas, interpolação, extrapolação).

Assim, e considerando as diferentes representações dos números racionais, notamos que um número racional pode ser representado por meio de figuras contínuas ou discretas, por meio de registros simbólicos numéricos ou algébricos, por meio do registro língua natural, do registro gráfico ou ainda por um diagrama. A figura 1 apresenta exemplos de números racionais em cada uma dessas representações.

Figura 1: Registros de representação semiótica dos números racionais. Fonte: Elaborada pelas autoras, baseadas nas informações de Silva, Santiago e Santos (2014).

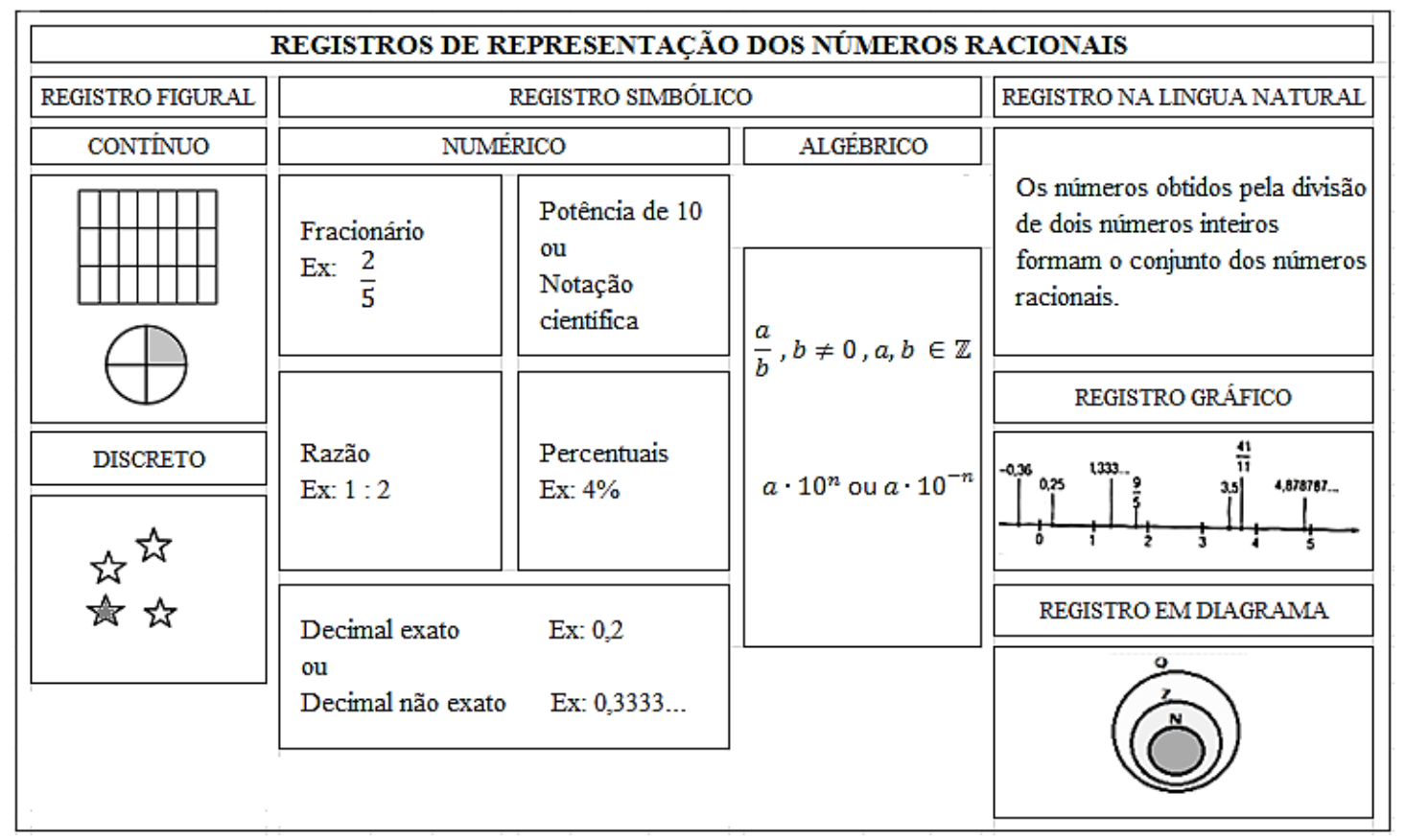

Diante desses diferentes registros de representação semiótica para os números racionais, percebe-se a importância de explorá-los em sala de aula, e que os alunos vivenciem no decorrer da escolarização diversas tarefas que proporcionem a articulação entre esses registros. 


\section{D|EDebates

Em seus trabalhos, Duval (2003; 2012) indica que a atividade matemática se manifesta em termos de transformações de representações semióticas, e as considera de dois tipos: os tratamentos e as conversões. O pesquisador defende que as dificuldades dos alunos estão relacionadas à diversidade e à complexidade dessas transformações, e que elas são essenciais para a aprendizagem dos conceitos matemáticos.

Duval denomina por tratamento as transformações internas a um mesmo registro de representação semiótica, como por exemplo, a adição de números racionais de um mesmo registro, conforme as três adições em registros diferentes exemplificadas a seguir:

i. Tratamento em registro decimal: $0,2+0,3=0,5$;

ii. Tratamento em registro fracionário: $\frac{1}{2}+\frac{1}{2}=\frac{1}{4}$;

iii. Tratamento em registro potência: $2 \cdot 10^{-2}+3 \cdot 10^{-2}=5 \cdot 10^{-2}$

De acordo com o pesquisador, as conversões são as transformações em que há mudança do registro de partida em relação ao registro de chegada, ou seja, existe transformação externa ao registro de saída. Por exemplo, uma atividade em que solicite escrever uma dízima periódica como 0,3333... em sua forma fracionária $\frac{1}{3}$, ou uma situação-problema, apresentada em linguagem natural, que para resolver exija uma representação numérica ou algébrica. Como linguagem natural consideramos a linguagem oficial no Brasil, o português.

Cada registro de representação possui regras próprias de tratamento. No que se refere aos números racionais, por exemplo, o tratamento realizado no registro fracionário exige o conhecimento de certas propriedades de soma, subtração, divisão, multiplicação, potência entre outros, que são específicas para esse registro, 
e que são muito diferentes das propriedades para o registro decimal ou na forma de potência.

Segundo Duval (2003), no processo de ensino, o tratamento é mais priorizado do que a conversão, por se apresentar como procedimentos de justificação. Já a conversão, do ponto de vista matemático, é vista como uma forma de [...] escolher o registro no qual os tratamentos a serem efetuados são mais econômicos, mais potentes, ou para obter um segundo registro que serve de suporte ou de guia aos tratamentos que se efetuam em um outro registro (DUVAL, 2003, p.16).

O pesquisador defende que para compreensão global de um conceito é a atividade de conversão que permite reconhecer o mesmo objeto em suas diferentes representações, e proporciona a coordenação entre diferentes registros de um mesmo objeto, pois passar de um registro de representação a outro não é somente mudar de tratamento, é também explicar as propriedades ou os aspectos diferentes de um mesmo objeto (DUVAL, 2003, p.22). Segundo Duval (2012), todas as representações são cognitivamente parciais em relação ao objeto que elas representam.

Duval (2003) nos alerta que no ensino, geralmente, estuda-se um sentido da conversão acreditando que automaticamente está se estudando o outro sentido. Contudo, o pesquisador destaca a importância de se realizar a conversão em ambos os sentidos, por meio de um processo de ida e vinda entre os registros, pois somente ao vivenciar diversas situações com essas características e ao transitar naturalmente de um registro para o outro irá acontecer a aprendizagem do conceito matemático.

Assim, levando em consideração a necessidade de se explorar os diferentes registros de representação semiótica e a importância de tarefas matemáticas que envolvem conversão, nos propomos a analisar livros didáticos do Ensino Fundamental aprovados pelo PNLD 2014, para investigar os registros presentes 
nestes livros, bem como as possibilidades de tratamento e conversão priorizados nas obras.

\section{METODOLOGIA}

Para a realização desta pesquisa nos propomos a analisar os livros didáticos de escolas do Núcleo Regional Estadual (NRE) de Campo Mourão - Paraná, com objetivo de analisar o que constam de tratamento e de conversão em relação aos registros de representação dos números racionais.

Para atingir nossos objetivos, buscamos no site do Fundo Nacional do Desenvolvimento da Educação - FNED² os dados em relação às escolas públicas pertencentes ao NRE de Campo Mourão, e os títulos das coleções de livros didáticos de matemática que essas instituições adotavam. Com esta investigação, verificamos que o NRE de Campo Mourão compreende 16 municípios e 53 escolas estaduais que ofertam os anos finais do ensino fundamental (6으 ao 9o ano); e que ao todo estas instituições de ensino adotam sete (07) coleções de livros didáticos de matemática. Essas informações, estão disponibilizadas no quadro 1.

Quadro 1: Livros Didáticos de Matemática adotados pelas escolas do NRE de Campo Mourão Paraná. Fonte: As autoras.

\begin{tabular}{|c|c|}
\hline Títulos dos Livros Didáticos & Quantidade de escolas que adotam a coleção \\
\hline Vontade de Saber Matemática & 23 \\
\hline Praticando Matemática - Edição renovada & 14 \\
\hline Projeto Teláris - Matemática & 8 \\
\hline Projeto Velear - Matemática & 4 \\
\hline Matemática - Bianchini & 2 \\
\hline Matemática: Teoria e contexto & 1 \\
\hline Projeto Araribá - Matemática & 1 \\
\hline
\end{tabular}

\footnotetext{
${ }^{2}$ Em www.fnde.gov.br/distribuicaosimadnet/iniciarSistema.action
} 


\section{D|EDebates

Como a pesquisa seria desenvolvida durante um ano de desenvolvimento de projeto de iniciação científica (período de agosto de 2014 a julho de 2015), precisávamos estabelecer um critério para selecionar algumas obras a serem analisadas, pois o curto período de tempo não seria suficiente para a acadêmica do 3o ano do Curso de Matemática estudar sobre a teoria dos registros de representação semiótica, analisar as coleções e escrever um artigo com os resultados alcançados.

Sendo assim, determinamos como critério de análise as das duas obras mais utilizadas nas escolas da região. Neste caso, de acordo com os dados apresentados no quadro 1, optamos pela análise das obras da coleção Vontade de Saber Matemática dos autores Joamir Souza e Patrícia Moreno Pataro e da coleção Praticando Matemática - Edição Renovada, dos autores Álvaro Andrini e Maria José Vasconcellos, que juntas representam as obras utilizadas por $68,9 \%$ das escolas deste NRE.

Após selecionarmos as obras a serem analisadas, entramos em contato com o NRE de Campo Mourão explicando nossa pesquisa e dizendo que para a sua realização precisaríamos das obras para serem analisadas. Após nosso contato, o NRE prontamente nos doou cinco das sete obras aprovadas pelo PNLD 2014, incluindo as duas obras que foram analisadas para esta pesquisa.

Ainda, por se tratar de uma pesquisa com curto tempo de duração, decidimos que a análise das obras se restringiria ao capítulo específico dos números racionais, presente nos livros do 8o ano do Ensino Fundamental. Ao analisar estes capítulos específicos sobre os números racionais, tivemos como objetivo investigar os registros de representação presentes nas obras, os tratamentos e possibilidades de conversões entre registros que são sugeridos no estudo do conjunto dos números racionais. 
Para identificar os diferentes registros, os tratamentos e as possibilidades de conversões entre registros presente nas obras, optamos por efetuar as observações em duas etapas:

1) Na introdução e abordagem do conceito de números racionais, incluindo os pressupostos teóricos e os: identificamos os registros utilizados e também as possibilidades de tratamento e conversões indicadas na obra.

2) Nas tarefas matemáticas propostas relacionadas aos números racionais: identificamos os registros presentes nas tarefas, os tratamentos e conversões solicitados ou possíveis de serem realizadas no momento da resolução; identificamos, também, os sentidos em que estas possíveis conversões estão priorizadas nas obras.

Para a análise das tarefas propostas nas obras, levamos em consideração a possiblidade de conversão que a tarefa solicitava, assim como as conversões que consideramos que o aluno possa fazer para chegar a uma resposta. Por exemplo, na tarefa exibida na figura 2 os autores solicitam que o aluno faça a mudança de registro, sendo que esta mudança deve ocorrer do registro numérico fracionário para o numérico decimal.

Figura 2: Tarefa do livro didático Vontade de Saber Matemática - 80 ano. Fonte: Souza e Pataro (2012, p.63).

27 Escreva as frações na forma de números
decimais.
$\begin{array}{llll}\text { a) } \frac{19}{4} 4,75 & \text { b) } \frac{1}{8} 0,125 & \text { c) } \frac{4}{3}{ }_{1,333} \text { d) } \frac{17}{8_{2,125}}\end{array}$

Já na tarefa da figura 3, é dada uma sentença em língua natural e a reposta resultará em um número na forma decimal, de acordo com a resposta no final do livro. Porém, essa mudança de registro não é direta, e o aluno pode utilizar de outros registros para chegar a resposta. 
Figura 3: Tarefa do livro didático Praticando Matemática - 8 ano. Fonte: Andrini e Vasconcellos (2012, p.18).

22 Dividindo $\mathrm{R} \$ 41,00$ igualmente entre 4 pessoas, quanto receberá cada uma?

Para essa tarefa, consideramos que o aluno possa transformar a sentença da língua natural para uma expressão no registro numérico razão, passando para o registro numérico decimal, desta forma: $41: 4=10,25$. E por ser uma tarefa envolvendo uma contextualização é possível escrever a resposta em forma de uma sentença em língua natural, fazendo a volta ao registro original: Cada pessoa receberá $R \$ 10,25$. Portanto, consideramos para essa tarefa a possibilidade das seguintes conversões: Registro em língua natural $\rightarrow$ registro numérico razão $\rightarrow$ registro numérico decimal $\rightarrow$ registro em língua natural.

Não consideramos que exista uma única forma de resolver a tarefa, e de escolha dos registros a serem utilizados, mas em nossas análises consideramos para cada tarefa uma possibilidade de conversão que o aluno poderá escolher.

\section{RESULTADOS E DISCUSSÃO}

As duas obras que foram objetos de nossas análises Vontade de Saber Matemática de Joamir Souza e Patrícia Moreno Pataro do 80 ano, e Praticando Matemática, dos autores Álvaro Andrini e Maria José Vasconcellos, destinada ao 8o ano serão denominadas daqui para a frente de LD-1 e LD-2, respectivamente.

A obra LD-1 é composta por 13 capítulos, sendo o terceiro capítulo destinado ao estudo dos conjuntos numéricos. A seção reservada para os números racionais se encontra entre as páginas 61 a 63. E outras tarefas complementares nas páginas 72 a 75, no grupo de tarefas que revisam o conteúdo trabalhado no capítulo. 
A LD-2 consiste de 14 unidades, sendo a primeira destinada ao estudo dos conjuntos numéricos. A abordagem dos números racionais e as tarefas propostas em relação ao conteúdo estão nas páginas de 14 a 18. Nesta mesma unidade foram identificadas também as tarefas do fim da unidade que abordavam o conceito de número racional, nos tópicos Revisando e Autoavaliação, páginas 30 a 34.

De acordo com as nossas análises, os registros de representação semiótica dos números racionais presentes na abordagem do conjunto dos números racionais nas obras LD-1 e LD-2 foram os registros: em língua natural (RLN), o numérico razão (RNR), o numérico decimal (RND), o numérico fracionário (RNF), o algébrico (RA), o registro em diagrama (RD), o gráfico $(R G)$ e o registro figural contínuo (RFC). O quadro 2 apresenta os registros explorados em cada obra.

Quadro 2: Registros de representação dos racionais presente abordagem do conteúdo. Fonte: As autoras

\begin{tabular}{|c|c|c|c|c|c|c|c|c|}
\hline Registros & RLN & RNR & RND & RNF & RA & RD & RG & RFC \\
\hline LD-1 & $\mathrm{X}$ & $\mathrm{X}$ & $\mathrm{X}$ & $\mathrm{X}$ & $\mathrm{X}$ & $\mathrm{X}$ & $\mathrm{X}$ & \\
\hline LD-2 & $\mathrm{X}$ & $\mathrm{X}$ & $\mathrm{X}$ & $\mathrm{X}$ & $\mathrm{X}$ & & $\mathrm{X}$ & $\mathrm{X}$ \\
\hline
\end{tabular}

Em ambas as obras, o registro língua natural aparece em dois momentos na abordagem do conteúdo dos números racionais: i) Para introduzir os números racionais por meio de uma situação na qual é necessária a divisão entre dois números inteiros e que resulta em um número não inteiro, expressando uma resposta na forma decimal ou fracionária, como no exemplo retirado de um dos livros abaixo (Figura 4); e ii) para fins explicativos de generalização dos números racionais com o auxílio do registro algébrico. 
Figura 4: Exemplo de abordagem dos números racionais utilizando língua natural. Fonte: Souza e Pataro (2012, p.61).

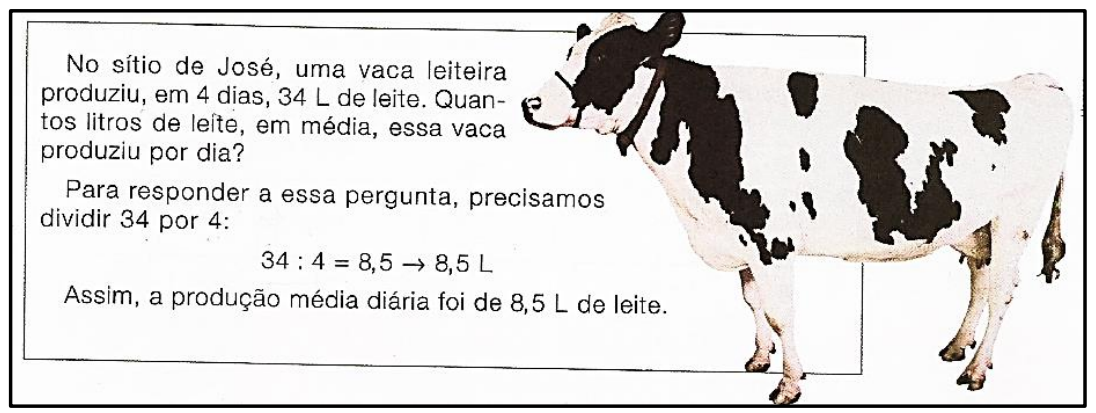

Ambas as obras apresentam um exemplo da representação na reta numérica de um número racional, na sua forma decimal ou fracionária. Porém, somente a LD-1 contempla o conjunto dos números racionais no registro em diagrama, e somente a LD-2 explora a representação figural contínua.

No que se refere às possibilidades de conversões entre os registros presentes nos exemplos contemplados durante a abordagem do conteúdo estão descritos no quadro 3.

Quadro 3: Conversões presentes nos exemplos na abordagem dos números racionais. Fonte: As autoras.

\begin{tabular}{|c|c|c|}
\hline Possibilidades de conversões & LD-1 & LD-2 \\
\hline$R L N \rightarrow R N R$ & $X$ & $X$ \\
\hline$R L N \rightarrow R F C$ & & $X$ \\
\hline$R N R \rightarrow R N D$ & & $X$ \\
\hline$R N R \rightarrow R N F$ & $X$ & $X$ \\
\hline$R N D \rightarrow R L N$ & $X$ & $X$ \\
\hline$R F C \rightarrow R L N$ & $X$ & \\
\hline$R N D \rightarrow R N F$ & & $X$ \\
\hline$R N F \rightarrow R N D$ & & $X$ \\
\hline
\end{tabular}

Destacamos que os exemplos em língua natural estão presentes nas duas obras, e eles apresentam a conversão para o registro numérico razão na LD-1 e para o figural contínuo na LD-2 e apresentam a volta para o registro em língua natural. 
As conversões do registro numérico fracionário para o numérico decimal estão presentes várias vezes em ambas as obras, sendo a conversão mais realizada nos exemplos - já que os outros tipos de conversão ocorrem uma única vez. Ao todo, conversão do numérico fracionário para o decimal é realizada quatro vezes no LD-1 e 15 vezes no LD-2, reforçando o sentido de que a divisão de dois números inteiros nem sempre será também um número inteiro. Porém somente a LD-1 faz o processo inverso, e ainda uma única vez, ou seja, parte do registro numérico decimal para se chegar ao numérico fracionário.

Em relação aos tratamentos presentes nas obras analisadas, apenas 0 tratamento no registro numérico fracionário, por meio de frações equivalentes, foi reconhecido em nossas análises, tanto na obra LD-1 quanto na LD-2.

Notamos que nas duas obras o tratamento fracionário, nos exemplos, ocorre apenas para mostrar que qualquer número inteiro também pode ser escrito na forma $\frac{a}{b}$, como apresenta o exemplo abaixo (Figura 5).

Figura 5: Exemplo de tratamento no registro numérico fracionário. Fonte: Souza e Pataro (2012, p.61).

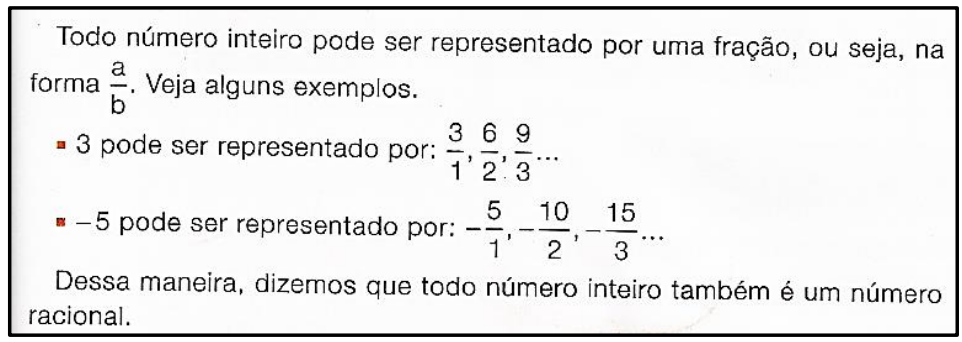

No que se referem às tarefas matemáticas propostas sobre os números racionais, foram identificadas 21 no LD-1 e 37 no LD-2. Em relação aos registros dessas tarefas, identificamos os registros de representação dos números racionais em que o aluno terá que considerar no momento da resolução presentes na estrutura das tarefas, para esta análise levamos em conta as respostas presentes no 
final do livro. Desse modo, os registros identificados foram o registro numérico decimal (RND), o numérico fracionário (RNF), o registro figural contínuo (RFC), o registro gráfico (RG), o numérico razão (RNR), o registro em diagrama (RD), o registro em língua natural (RLN) e o numérico percentual (RNP). Um resumo dos registos identificados nas tarefas propostas aos alunos está apresentado no quadro 4.

Quadro 4: Registros de representação dos números racionais presente nas tarefas. Fonte: As autoras.

\begin{tabular}{|c|c|c|c|c|c|c|c|c|}
\hline Registros & RND & RNF & RFC & RG & RNR & RD & RLN & RNP \\
\hline LD-1 & $\mathrm{X}$ & $\mathrm{X}$ & $\mathrm{X}$ & $\mathrm{X}$ & $\mathrm{X}$ & $\mathrm{X}$ & & \\
\hline LD-2 & $\mathrm{X}$ & $\mathrm{X}$ & $\mathrm{X}$ & $\mathrm{X}$ & $\mathrm{X}$ & & $\mathrm{X}$ & $\mathrm{X}$ \\
\hline
\end{tabular}

Assim como na abordagem do conteúdo, as duas obras continuam fazendo a abordagem dos registros numérico decimal, fracionário e razão e do registro gráfico. Podemos observar também que o registro figural contínuo passa a ser abordado em tarefas na obra LD-1, mas que ela deixa de explorar o registro em língua natural.

Do mesmo modo que na abordagem ao conteúdo, apenas o LD-1 apresenta o registro em diagrama nas tarefas propostas. E o LD-2 apresenta em uma de suas tarefas o registro numérico percentual que até então não tinha aparecido.

As conversões solicitadas entre registros ou que podem ser realizadas pelos alunos ao resolverem as tarefas de cada livro estão expressas no quadro 5, de acordo com o número de tarefas em que essas ações são necessárias. 
Quadro 5: Quantitativo de conversões possíveis nas tarefas de números racionais

Fonte: as autoras

\begin{tabular}{|c|c|c|}
\hline Conversões & LD-1 & LD-2 \\
\hline$R N R \rightarrow R N D$ & - & 13 \\
\hline$R N F \rightarrow R N D$ & 9 & - \\
\hline$R N F \rightarrow R G$ & 3 & 12 \\
\hline$R N D \rightarrow R N F$ & 3 & 2 \\
\hline$R N D \rightarrow R L N$ & - & - \\
\hline$R N D \rightarrow R G$ & 3 & 2 \\
\hline$R L N \rightarrow R N R$ & - & 1 \\
\hline$R L N \rightarrow R N D$ & - & 3 \\
\hline$R L N \rightarrow R A$ & - & 1 \\
\hline$R L N \rightarrow R N P$ & - & 2 \\
\hline$R G \rightarrow R N F$ & - & 3 \\
\hline$R G \rightarrow R N D$ & - & 1 \\
\hline$R F C \rightarrow R N F$ & 1 & 3 \\
\hline$R A \rightarrow R L N$ & - & 1 \\
\hline$R N P \rightarrow R L N$ & - & 46 \\
\hline
\end{tabular}

As análises mostram que a possibilidade de conversão do registro numérico fracionário para o numérico decimal foi a mais realizada nas duas obras, sendo possíveis em 9 tarefas na LD-1 e em 13 tarefas na LD-2. Já no sentido contrário, do registro numérico decimal para o numérico fracionário, aconteceu quase na mesma proporção na LD-2, 12 vezes. No entanto, esta conversão foi menos solicitada na LD1 em relação ao sentido contrário, apenas três vezes. Percebemos, ainda, que a conversão do registro numérico decimal para o numérico fracionário, não havia sido explorada nos exemplos da obra LD-2, mas foi contemplada nas tarefas propostas.

As tarefas cujo registro de partida é o de língua natural estão presentes apenas no LD-2, sendo ao total, sete tarefas dentre as 37 identificadas na obra. De acordo com Duval (2012), problemas propostos em língua natural são importantes para a aprendizagem matemática, pois favorecem conversão entre registros: [...] esta 
conversão interna não é feita diretamente, ela passa por representações intermediárias (DUVAL, 2012, p. 295).

Nas tarefas que proporcionam a conversão do registro em língua natural para o numérico razão, consideramos aquelas que indicam uma situação de divisão e nas tarefas em que consideramos que o registro de partida em língua natural proporcionando uma passagem para o registro algébrico, foram consideradas aquelas em que podem ser resolvidas usando um pensamento proporcional (Figura 6). Essas tarefas, cujo registro de partida aparece em língua natural, ainda proporcionam que as respostas sejam expressas em língua natural, fazendo a volta para o mesmo registro de partida, fato que é importante para a compreensão do conceito, do ponto de vista de Duval.

Figura 6: Exemplo de possibilidade de conversão do registro língua natural para o algébrico. Fonte: Andrini e Vasconcellos (2012, p.18).

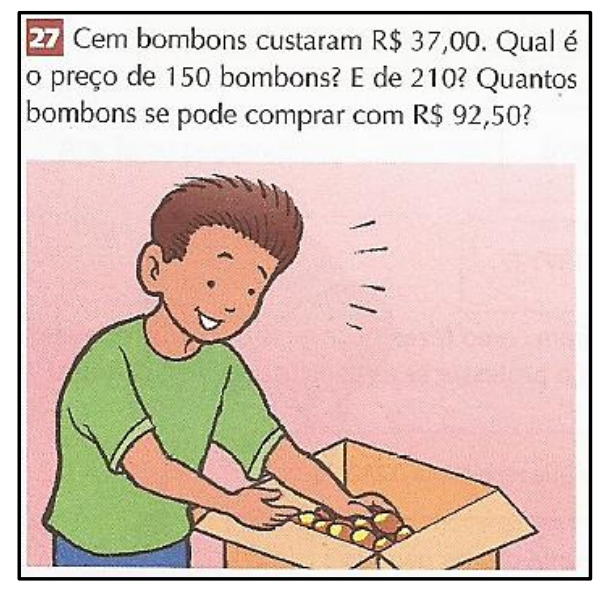

Quanto às conversões entre os registros numérico fracionário ou numérico decimal e o registro gráfico, o livro didático LD-1 priorizou apenas a conversão que tem como registro de partida os registros numéricos fracionários e decimais para o registro gráfico, enquanto o LD-2 priorizou o sentido contrário. 
A conversão com o registro figural contínuo aconteceu em um único sentido, como sendo o registro de partida, e com o registro numérico fracionário como registro de chegada, aparecendo uma vez em cada uma das obras. Já a conversão do registro numérico razão para o registro numérico decimal foi identificado apenas na LD-2, nas tarefas em que tiveram a língua natural como registro de partida.

Em relação aos tratamentos identificados nas tarefas, eles ocorrem não somente no registro numérico fracionário conforme mostram os exemplos das obras, mas também nos registros numérico decimal e algébrico como podemos observar no quadro 6:

Quadro 6: Quantitativo de conversões relacionados as tarefas dos números racionais Fonte: As autoras

\begin{tabular}{|c|c|c|}
\hline Tratamentos & LD-1 & LD-2 \\
\hline RNF & 2 & 11 \\
\hline RND & 1 & 3 \\
\hline RA & - & 4 \\
\hline & 3 & 18 \\
\hline
\end{tabular}

Conforme observado no quadro 6, o tratamento no registro numérico fracionário também é o mais solicitado nas tarefas de ambas as obras analisadas. Já o tratamento no registro algébrico pode ser realizado apenas nas tarefas da obra LD2, naquelas que indicam ser necessária a adoção de um pensamento proporcional (figura 6), na qual o aluno pode escrever uma relação de proporcionalidade e realizar o tratamento algébrico para obtenção das repostas, como por exemplo: $\frac{100}{150}=\frac{37}{x}$.

\section{CONSIDERAÇÕES FINAIS}

Nossas análises mostram que em relação ao conceito de número racional e os diferentes registros de representação semiótica, tratamentos e conversões, as obras analisadas apresentam algumas semelhanças, mas também indicam diferenças 
significativas tanto na abordagem e explicações do conteúdo quanto em suas tarefas propostas.

Notamos que ambas as obras introduzem os números racionais por meio de situações contextualizadas, por meio do registro língua natural em que se faz necessário o uso do registro numérico fracionário para representar a divisão entre dois números inteiros, para indicar que o resultado não se trata de um número inteiro. Porém, percebemos que a abordagem do registro em língua natural só continua a ocorrer no LD-2 nas tarefas propostas pelos autores.

Consideramos positivo o fato de a obra LD-2 continuar a explorar o registro língua natural, e propiciar aos alunos a resolução de problemas nesse registro durante o estudo dos números racionais. Pois, segundo Duval (2012, p. 295), "A língua natural deve ser considerada, ao mesmo tempo, um registro de partida e um registro de chegada. [...] esta conversão interna não é feita diretamente, ela passa por representações intermediárias". Ou seja, o pesquisador menciona que o registro em língua natural proporciona ao menos duas conversões, da língua natural para um outro registro, que pode ser numérico, algébrico, gráfico, figural, e a volta deste registro para a língua natural, que se trata da resposta para o problema solicitado.

A conversão do registro numérico fracionário para o numérico decimal é a conversão que está mais presente em ambas as obras, tanto nos exemplos durante a abordagem do conteúdo quanto nas tarefas propostas. No entanto, a conversão do registro numérico decimal para o numérico fracionário não ocorre no LD-1 na abordagem ao conteúdo, ela acontece apenas nas tarefas e em menor quantidade com relação ao sentido contrário; e, na LD-2, essa conversão está presente uma única vez na abordagem ao conteúdo, e aparece com quase a mesma frequência que no sentido contrário. 


\section{D|EDebates

O motivo das obras priorizarem o registro fracionário como registro de partida, pode se justificar por estar relacionado à importância em que é dada à representação fracionária para se representar os números racionais, fato constatado na pesquisa de Rezende (2013). Esse fato também corrobora com a afirmação de Duval (2003) de que a educação tende a priorizar um sentido da conversão, ficando implícito que o aluno também estará aprendendo o sentido contrário da referida conversão.

Além disso, enquanto o LD-1 solicitou a conversão dos registros numéricos decimal ou fracionário para o registro gráfico nas tarefas, o LD-2 solicitou essa conversão apenas no sentido contrário, ou seja, dado um registro gráfico é necessária a localização de pontos em sua forma fracionário ou decimal.

Em nossas análises, o registro em diagrama só foi identificado no LD-1 e o numérico porcentagem no LD-2. Já o registro figural discreto e o numérico potência de dez, não foram identificados na abordagem feita ao conjunto dos números racionais em nenhuma das obras analisadas.

Sendo assim, considerando as diferenças significativas em relação aos registros de representação e as conversões entre estes registros identificados nas obras analisadas, alertamos para a importância do momento de escolha do livro didático. Pois, se o livro ainda é o principal instrumento para auxiliar a prática pedagógica do professor em sala de aula, e se as coleções apresentam características distintas entre si, é imprescindível que a sua escolha seja cautelosa no sentido de atender as especificidades do ensino de matemática, uma vez que, conforme mostramos com esta pesquisa, as obras apresentam diferenças entre si, no que se refere aos registros de representação semióticas contemplados em cada obra.

Do ponto de vista da compreensão de conceitos matemáticos, nossas análises mostram a importância de o professor complementar a preparação de suas aulas 
com outros livros didáticos e materiais, propiciando aos alunos experiências com tarefas matemáticas que visam propiciar a conversão entre os diferentes registros. Pois, segundo Duval, este é o caminho para levar os alunos a reconhecer o mesmo objeto matemático (abstrato) em suas diferentes representações, culminado com a compreensão dos conceitos estudados.

\section{AGRADECIMENTOS}

Agradecemos à Fundação Araucária pela bolsa de Iniciação Científica, concedida para a primeira autora deste trabalho, durante o período de agosto de 2013 a julho de 2014.

\section{REFERÊNCIAS}

ANDRINI, A.; VASCONCELLOS, M. J. Praticando Matemática - 8o ano. São Paulo: Editora do Brasil, 2012.

BRASIL. Ministério da Educação e do Desporto. Secretaria de Educação Fundamental. Parâmetros Curriculares Nacionais (1ㅁa $4 \underline{a}$ series): Matemática. Brasília, 1997.

DUVAL, R.; FREITAS, J. L. M.; REZENDE, V. Entrevista: Raymond Duval e a Teoria dos Registros de Representação Semiótica. Revista Paranaense de Educação Matemática, v. 2, p. 10-34, 2013.

DUVAL, R. Registros de Representação Semiótica e Funcionamento Cognitivo do pensamento. Revemat, Florianópolis, v. 07, n. 2, p.266-297, 2012.

DUVAL, R. Registros de Representações Semióticas e Funcionamento Cognitivo da Compreensão em Matemática. In: MACHADO, S. D. A. (org.). Aprendizagem em matemática: registros de representação semiótica. Campinas, São Paulo: Papirus, p. 11-33, 2003. 


\section{E Debates \\ em Educação Científica e Tecnológica \\ ISSN - 2236-2150 (Eletrônica)}

REZENDE, V. Conhecimentos sobre números irracionais mobilizados por alunos

brasileiros e franceses: um estudo com alunos concluintes de três níveis de ensino.

(Tese de doutorado). Universidade Estadual de Maringá, Maringá, 2013.

SILVA, F. A. F.; SANTIAGO, M. M. L.; SANTOS, M. C. Significados e Representações dos

Números Racionais Abordados no Exame Nacional do Ensino Médio - ENEM. Bolema, Rio Claro, v. 28, n. 50, p. 1485-1504, 2014.

SOUZA, J. PATARO, P. M. Vontade de Saber Matemática - 80 ano. São Paulo: FTD, 2012.

Recebido em: Setembro de 2016. Publicado em: Dezembro de 2017.

'Estudante de Mestrado do Programa de Pós-Graduação em Educação em Ciências e Educação Matemática - PPGECEM da UNIOESTE, e docente colaboradora do Colegiado de Matemática da UNESPAR.

ii Docente do Colegiado de Matemática da UNESPAR, e docente do quadro permanente do Programa de Pós-Graduação em Educação em Ciências e Educação Matemática - PPGECEM da UNIOESTE, orientadora deste trabalho. 